\title{
Simulação da produção utilizando técnica de dinâmica de sistemas em uma indústria de vidro: estudo de caso em uma processadora de vidro
}

\author{
RESUMO
}

Raphael Gallegos

raphael.gallegos@prof.una.br

Centro Universitário UNA (UNA), Belo

Horizonte, MG, Brasil

\begin{abstract}
As empresas cada vez mais buscam por melhorias em seus processos produtivos. A identificação de gargalos ou perdas em processos produtivos é, muitas vezes, complexo para ser identificado ou solucionado sem ajuda de softwares de simulação. Os processos muitas vezes não são lineares, o que dificulta o gestor a trabalhar com formas convencionais de Estudos de Tempo, Balanceamento de Linha, Balanceamento de Fluxo ou Carga, ou qualquer outra técnica que ele não possa utilizar softwares para simulação. $A$ simulação é um processo de criar e experimentar um sistema por meio de modelos matemáticos. O sistema é composto por entradas (inputs) e saídas (outputs) e as mesmas oferecem um resultado para alguma finalidade. O presente artigo apresenta um estudo de caso para uma indústria do ramo vidreiro, utilizando técnicas de simulação por meio da Dinâmica de Sistemas. Foram simulados 07 cenários que contemplam o aumento gradual na produtividade de cada setor. Dentre todos os cenários analisados o que apresentou melhor resultado para produção no setor do Forno, foi o último cenário. Esse aumento foi de 9,22\% com utilização da mesma mão de obra e dentro do horário de trabalho da organização que é de oito horas diárias.
\end{abstract}

PALAVRAS-CHAVE: Modelagem. Dinâmica de Sistemas. Industrialização de Vidro. 


\section{INTRODUÇÃO}

Nos ambientes de mercados que estão cada vez mais competitivos, as empresas de pequeno, médio e grande porte, buscam soluções para melhorar sua produtividade, diminuir seus custos e aumentar a satisfação de seus clientes. A produção apresenta processos de fabricação cada vez mais complexos, os mix de produção são cada vez maiores. Isso tudo com intuito de atender as necessidades dos mercados cada vez mais exigentes e globalizados.

Para sobreviver nesse cenário, que está em constante mudança, os gestores buscam soluções para problemas relacionados a gargalos, desperdícios com relação a estoque, ociosidade de máquina, mão de obra, movimentação desnecessária, retrabalhos. Todos esses problemas geram perdas, para a organização, e essas perdas podem levar a uma diminuição nas vendas que se não for tratada de maneira correta pode trazer o encerramento das atividades.

Nesse atual sistema existe concorrência para praticamente todos os tipos de produto e serviço, e se a organização não consegue atender com melhor prazo e ofertar o melhor preço de venda, o cliente passa a comprar do concorrente.

Quando a companhia trabalha com foco em pessoas, qualidade e quantidade ela passa a ter um desempenho melhor do que a que não trabalha, e esse desempenho altera a lucratividade no final do mês.

Hoje é comum nas organizações a busca ao lidar com gargalos e desperdícios, a opção por realizar estudos simulados em vez de testes que afetem diretamente a rotina da organização. Para tal é necessário recorrer a softwares de simulação que quando bem empregados trazem bons resultados para as organizações, pois os mesmos permitem simular diferentes cenários e propor diferentes alternativas sem que a companhia necessite fazer alguma mudança física.

Desta forma esse artigo buscou estudar por meio de simulação de processos utilizando Dinâmica de Sistemas, a melhoria da produtividade em uma indústria do ramo vidreiro. $O$ nome da empresa em questão não pode ser revelado por motivo de solicitação de sigilo da mesma, sendo denominada neste estudo como Empresa Z.

\section{REFERENCIAL TEÓRICO}

\section{GESTÃO DA PRODUÇÃO}

De acordo com Rusivel et al. (2017) as organizações apresentam processos de produção complexos e trabalham com mix de produtos, tornando difícil a identificação de gargalos e perdas dentro dos processos. Essas mesmas empresas apresentam desperdícios relacionados a estoque, ociosidade de máquina, mão de obra, movimentação desnecessária, retrabalhos dentre outras coisas.

Castro (2018) afirma que o sistema de produção pode ser considerado como processos que recebem entradas (inputs), transformações e saídas (outputs). Os inputs podem ser considerados como, máquinas, estruturas físicas funcionários dentre outros. Os mesmos têm como objetivo transformar os recursos que 
podem ser considerados como insumos, clientes e informações. Feito a transformação ocorrem as saídas (outputs) por meio de serviços ou produtos acabados.

Rusivel et al. (2017) complementa dizendo que no sistema Produção Enxuta, tudo aquilo que não agrega valor ao produto, visto sob a ótica do cliente, é considerado desperdício e todo desperdício apenas adiciona custo e tempo sendo considerado como sintoma e não a causa raiz do problema.

O mesmo autor afirma que para existir uma Produção Enxuta é necessária a eliminação de sete tipos clássicos de desperdícios, também denominado de perdas, existentes dentro de uma organização. Podem ser citadas as perdas por superprodução, transporte, processamento, fabricação de produtos defeituosos, movimentação, espera e existência de estoques. Trabalhando com os pontos que são: pessoas, qualidade e quantidade, consegue-se minimizar, as sete perdas no processo.

De acordo Ramon; Machado (2016) a opção por realizar estudos simulados em vez de testes que afetem diretamente a rotina da organização é comum nos mais diversos setores da economia, ao buscarem lidar com gargalos e desperdícios, pois evita expor as organizações em riscos elevados e muitas vezes desnecessários.

\section{SIMULAÇÃO}

A simulação pode ser classificada em duas grandes categorias: a simulação computacional e a simulação não computacional. A simulação computacional, é aquela que requer o uso de softwares para o seu desenvolvimento, devido à complexidade e quantidade de cálculos realizados. A simulação não computacional, é aquela que não necessita de um computador para ser realizada, como por exemplo, quando um projetista utiliza um protótipo em escala reduzida de uma determinada montagem (carro, avião, prédio, etc) (RABELO et al., 2017).

Os autores Pereira; Dantas (2017) definem que simulação é um processo de criar e experimentar um sistema por meio de modelos matemáticos. O sistema é composto por entradas (inputs) e saídas (outputs) e as mesmas oferecem um resultado para alguma finalidade. Essa técnica possibilita a imitação do sistema real que permite simular desde funcionamento de um banco como a produção de uma fábrica.

Os autores Vinhote; Silva; Oliveira (2017) complementam a definição de modelagem e simulação, como uma atividade ou situação que reproduz uma condição real e que pode ser utilizada para testar qualquer coisa, permitindo imitar um procedimento real em menor tempo e com menor custo e com um melhor estudo do que vai acontecer e de como consertar erros que gerariam grandes gastos. O autor Bovo (2015) complementa afirmando que os modelos de simulação apresentam três tipos de representação: físicas, matemáticas ou lógicas de um sistema, processo ou fenômeno.

A técnica de simulação permite testes como "what if", no qual pode se alterar um ou mais parâmetros do modelo e observar os resultados de saída. Em cenários de modelagem, o modelo é submetido a entradas conhecidas, obtidas por meio da análise de dados históricos ou por meio do estudo de tempos e 
movimentos, e após a simulação computacional, retorna as respostas de saída do modelo (BOVO, 2015).

Os autores Antônio; Júnior; Anzanello, (2016) afirmam que simulação pode ser definida como a reprodução de um comportamento por meio de modelos que descrevam seus processos. Após a construção dos modelos as variáveis que o compõem podem ser manipuladas para entender o comportamento do modelo e analisar o efeito da alteração no modelo. A simulação não prescreve a solução ideal para o problema, mas permite fazer comparações de várias alternativas de solução e é possível obter propriedades do sistema em um tempo menor do que se estivesse fazendo observação do sistema em tempo real.

\section{DINÂMICA DE SISTEMAS}

O sistema é um conjunto de elementos que são independentes, possuem uma interação de forma estável onde as alterações em qualquer elemento afetam todo o conjunto. Inicialmente para definição de um sistema é preciso determinar quem são os elementos e qual a relação que existe entre eles. É necessário diferenciar entre dois modelos. $O$ primeiro que é de previsão onde a oposição aos modelos de gestão no caso ( $x$ e y), são projetados para apresentar informações precisas do status futuro do sistema modelado. O segundo modelo que são modelos de gestão que, por possuir comparações de igual utilidade não exige total precisão. Este é o tipo de modelo adotado na Dinâmica de Sistemas (OLIVEIRA BERNARDO; RONALDO TAVARES SANTOS; GERALDO MENDES MIRANDA, 2017).

De acordo com Maldonado; Vaz, (2016) os últimos quase 60 anos, o uso da metodologia conhecida como Dinâmica de Sistemas cresceu substancialmente, sendo aplicada a problemas da gestão, economia, ciências ambientais, fenômenos sociais e educação. Para ZHAN et al., (2012) a Dinâmica de Sistemas, foi introduzido por Jay Forrester na década de 1960 e forneceu uma metodologia eficaz para o melhor entendimento de problemas de gestão complexos e de larga escala. Ela é uma metodologia eficaz para lidar com problemas dinâmicos. Ainda de acordo com os autores a compreensão de como os processos, informações e gerenciamento existentes interagem na criação da dinâmica das variáveis de interesse é o ponto da metodologia da Dinâmica de Sistema. Esses fatores e as relações entre eles constituem a estrutura do sistema. É necessário, no método de Dinâmica do Sistema, que o modelo forneça uma explicação válida do sistema atual. A Dinâmica de Sistemas tem sido usado em muitas áreas, incluindo análise social e econômica sistemas agrícolas gestão de recursos naturais e desenvolvimento sustentável.

Existem duas premissas básicas para que Dinâmica de Sistemas possa funcionar. A primeira delas refere-se à importância da montagem da estrutura do sistema dos elementos físicos que a compõem, das regras de decisão que estão vinculadas e das inter-relações para explicar o comportamento do sistema em estudo. A segunda premissa está relacionada com o fenômeno da acumulação. São as respostas do sistema às ações dos tomadores de decisão apresenta-se na forma da acumulação ou redução de matéria, energia ou informação. Pode ser citado como exemplo a redução ou aumento do estoque de produtos em processos durante uma operação (ZHAN et al., 2012). 
A Dinâmica de Sistemas possui uma perspectiva e um conjunto de ferramentas conceituais que permitem entender a estrutura de sistemas complexos. Ela utiliza da simulação para investigar como um sistema responderá, dinamicamente, a um conjunto de mudanças. (OMOGBAI; SALONITIS, 2016)

O autor Omogbai; Salonitis (2016) complementa dizendo que a Dinâmica de Sistemas, tem sido usada para controlar o custo da qualidade, para investigar o desempenho de uma célula enxuta sob incerteza, para melhorar o desempenho de uma operação de fundição e como uma ferramenta de melhoria de produtividade em uma gráfica. Ela também tem sido usada como melhoria no tempo de processo.

De acordo com Zhan et al (2012), os principais elementos de um modelo de Dinâmica de Sistema são variáveis de estoque, fluxos e auxiliares. As variáveis de estoque ou de nível representam associações importantes no sistema. Os fluxos variáveis também são conhecidos por: dinâmica do modelo, que é determinada pelos ciclos de realimentação do modelo. Cada seta no diagrama indica a influência de um elemento no outro. A influência é considerada negativa (-) se uma diminuição em um elemento causar um aumento em outro ou positivo (+) no caso oposto.

\section{DIAGRAMAS DE ESTOQUE E FLUXO}

De acordo Maldonado; Vaz (2016) os Diagramas de Estoque e Fluxo (SFD) são baseados na construção de sistemas de equações diferenciais que por sua vez são resolvidos com a ajuda de softwares especializados como, por exemplo, STELLA/iThink ${ }^{\circledast}$ e o Vensim ${ }^{\circledast}$. Essas equações são compostas por variáveis que representam a acumulação no sistema denominada de estoques. Os fluxos são responsáveis por aumentar ou diminuir esses estoques e variáveis auxiliares. Matematicamente, o estoque representa a resolução de uma equação diferencial dentro do sistema de equações.

O autor omogbai; Salonitis (2016) complementa o estudo de Diagrama de Estoque e Fluxo afirmando que ela é uma técnica de modelagem, consistindo de um diagrama de laço causal, que mapeia as variáveis essenciais do sistema e as influências causais entre elas. Os estoques gerados são acúmulos, expressos em quantidades que caracterizam o sistema. Os fluxos são taxas, tipicamente em quantidades ao longo de um período especificado, que esgotam ou reabastecem o nível de estoque, como por exemplo, a taxa de embarque e a taxa de produção, respectivamente, para um sistema de manufatura. Para simulação é necessário um conjunto de equações que descrevam as várias relações causais. Posteriormente, ele pode ser usado para análise de cenário, otimização e outras análises e aplicações de simulação.

\section{METODOLOGIA}

Para realização desse estudo foram coletados dados por meio de visita in loco, em uma empresa de beneficiamento de vidro, especificamente uma indústria beneficiadora que fornece vidros para construção civil. O nome da empresa em questão não pode ser revelado por motivo de solicitação de sigilo da mesma, sendo denominada neste estudo como Empresa $Z$. 
Para que houvesse a possibilidade de modelar e simular cenários alternativos para essa organização foi necessário seguir inicialmente as seguintes etapas:

a) Visita inicial: Foi realizada uma visita técnica com o intuito de entender o funcionamento da organização, ou seja, saber quais eram as entradas, os processos e as saídas;

b) Construção de fluxograma: Construiu-se um fluxograma do produto oferecido;

c) Definição de amostra: Após a construção do fluxograma, definiu-se as amostras de dados coletados para construção do modelo;

d) Modelagem e simulação: Nessa etapa foi utilizado o software Vensim ${ }^{\circledR}$ para criação do modelo e posteriormente ser feito a criação de cenários. Foram propostos 07 cenários com duração de 22 dias simulados.

\section{PREMISSAS DO MODELO}

Para poder ser feita a modelagem do sistema e os cenários apresentados fossem condizentes com a realidade da Empresa Z, algumas premissas tiveram que ser seguidas.

a) Como a organização trabalha com vários produtos foi determinado que o vidro temperado fosse o produto, pois o mesmo é o que tem maior demanda pelos clientes;

b) A ordem para fabricação do produto pode ser visualizada por meio do fluxograma da Figura 1;

c) Os dados para simulação foram coletados para cada setor de produção considerando 32 dias;

d) Após os dados coletados foram obtida por meio de planilha de Excel as Equações correspondentes a cada um dos setores. Essas mesmas equações foram utilizadas no modelo. A escolha específica de cada equação se deve ao fato dela ajustar melhor a realidade da organização o que possibilitou que o modelo seja próximo da realidade vivenciada pela empresa;

e) A simulação foi feita considerando 22 dias. A empresa trabalha de segunda a sexta feira, cada dia corresponde a 08 horas de serviço / produção;

f) A unidade de medida adotada foi metros;

g) A entrada inicial do sistema inicia com "Vendas Diárias", ela alimenta o primeiro setor denominado "Entrada Corte";

h) A "Saída Corte" alimenta a entrada do próximo setor chamado de "Entrada Lapidação" e assim sucessivamente;

i) Foram levantadas as metragens de retrabalho de cada setor e o mesmo gerou o "Retrabalho Total" que também alimenta o sistema. Nesse caso entendesse que retrabalho é refazer novamente a peça, 
por consequência o retrabalho alimenta a "Entrada Corte" junto com

"Vendas Diárias".

\section{AMOSTRAGEM}

O tempo coletado para elaboração da simulação foi de 32 dias (segunda a sexta feira) considerando 08 horas a jornada de trabalho. Por meio dos dados coletados foi obtida equações que representam o comportamento de cada atividade desenvolvida na empresa.

Sendo:

$y=$ metragem

$\mathrm{x}=$ tempo em horas

O fluxo do processo inicia com as otimizações de pedidos que são enviados para a mesa de Corte Automática. A mesma carrega e corta todo o vidro de acordo com a programação do dia. As Equações 1 e 2 mostram a metragem relacionadas a essas duas atividades.

$$
\begin{aligned}
& \text { Corte Automático - Equação } 1 \\
& y=513,53 x^{0,1065} \\
& \text { Vendas - Equação } 2 \\
& y=753,15 x^{0,0794}
\end{aligned}
$$

A segunda etapa do processo inicia com a Lapidação do vidro, onde é feito o abaste das peças até chegarem na dimensão especificada pelo cliente. São utilizadas durante o processo quatro máquinas (Lapidadoras), que trabalham em sequência, ou seja, o vidro é passado uma única vez na máquina. A Equação 3 representa todo o vidro lapidado durante uma jornada de trabalho.

$$
\begin{aligned}
& \text { Lapidação - Equação } 2 \\
& \mathrm{y}=494,97 \mathrm{x}^{0,131}
\end{aligned}
$$

O terceiro setor é denominado Marcação I e Marcação II, nesses setores é feito a marcação das ferragens de acordo com a solicitação de cada cliente, as mesmas passam para furos e recortes. A Marcação II é feita apenas peças de furação e a Marcação I recebe os dois tipos de marcação. As Equações 4 e 5 representam a metragem produzida em uma jornada de trabalho para essas duas atividades. 


$$
\begin{aligned}
& \text { Marcação I - Equação } 4 \\
& \mathrm{y}=244,19 \mathrm{x}^{0,1941}
\end{aligned}
$$

$$
\begin{aligned}
& \text { Marcação II - Equação } 5 \\
& \mathrm{y}=247,19 \mathrm{x}^{0,0576}
\end{aligned}
$$

O quarto setor é denominado Conferência, nessa etapa é verificado no vidro qualquer tipo de anomalia ou qualquer inconformidade com projeto solicitado pelo cliente. A Equação 6 representam a metragem conferida em um dia de trabalho.

$$
\begin{aligned}
& \text { Conferência - Equação } 6 \\
& \mathrm{y}=555,55 \mathrm{x}^{0,0066}
\end{aligned}
$$

A última etapa do processo é a tempera do vidro, que consiste no aquecimento a aproximadamente 600 graus Celsius e em seguida o mesmo é resfriado a temperatura ambiente. A metragem de tempera gerada em um dia de trabalho pode ser representada pela Equação 7.

$$
\begin{aligned}
& \text { Forno - Equação } 7 \\
& y=0,0415 x^{3}-1,7489 x^{2}+25,115 x+640
\end{aligned}
$$

Todos os setores geram algum tipo de retrabalho que deve ser considerado. Para essas peças é feita uma nova otimização e as mesmas são cortadas na mesa de Corte Automático. As Equações 8 a 12 representam a metragem gerada em cada setor e na Figura 1 é possível ver o Fluxograma produção da tempera do vidro.

$$
\text { Retrabalho Corte - Equação } 8
$$$$
\mathrm{y}=1,4426 \mathrm{x}^{0,4295}
$$

Retrabalho Lapidação - Equação 9

$\mathrm{y}=18,924 \mathrm{x}^{-0,246}$

Retrabalho Marcação I - Equação 10

$y=0,0009 x^{3}-0,0401 x^{2}+0,4982 x+1,4437$

Retrabalho Conferência - Equação 11

$\mathrm{y}=0,0034 \mathrm{x}^{2}+0,0405 \mathrm{x}+1,5976$ 
Retrabalho Saída do Forno - Equação 12

$\mathrm{y}=0,0815 \mathrm{x}+0,3619$

Figura 01 - Fluxograma Vidro Temperado

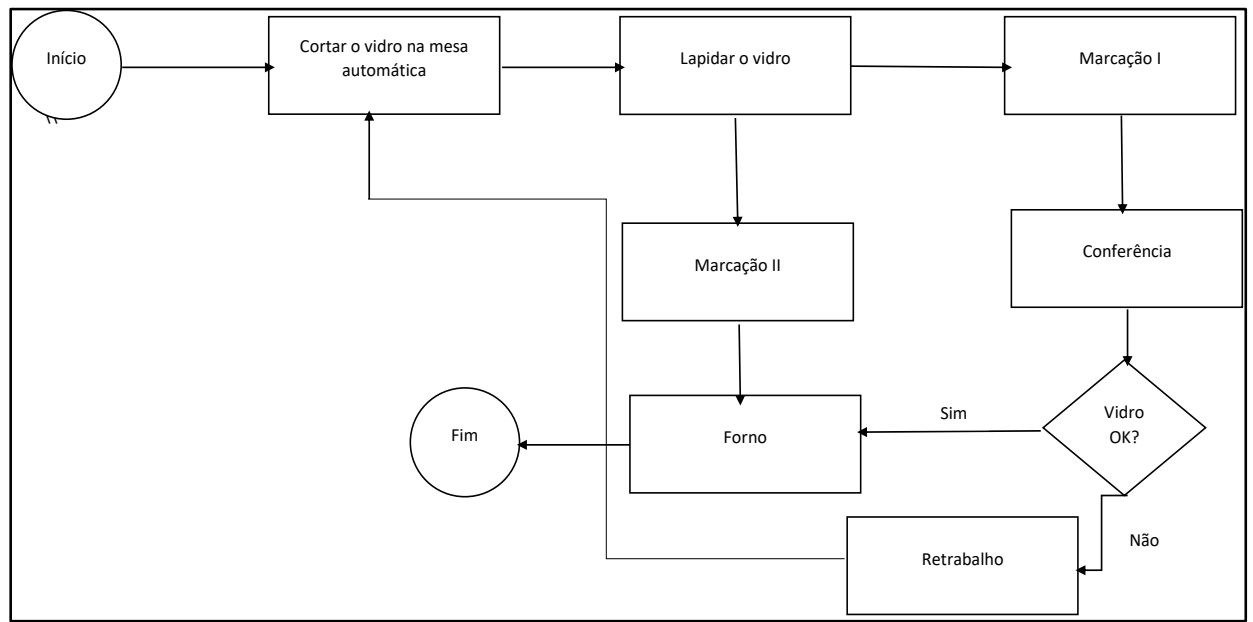

Fonte: Autoria própria (2018)

\section{RESULTADOS E DISCUSSÕES}

\section{CARACTERIZAÇÃO DA EMPRESA Z}

A empresa $Z$ é uma indústria de processamento de vidro plano, onde a mesma faz a têmpera do vidro. A têmpera consiste em aquecer o vidro seguido de um resfriamento rápido até chegar à temperatura ambiente. Esse choque térmico causado no vidro lhe concede uma resistência mecânica 10 vezes a mais do que um vidro comum, resiste a uma temperatura de trabalho de até 250 graus Celsius e o torna um vidro de segurança, pois o mesmo quando quebra, estilhaça em pequenos fragmentos sem bordas cortantes. Essa indústria está localizada no estado de Minas Gerais e conta com total de 82 colaboradores. Sua principal atividade é fornecer vidros temperados destinados à construção civil.

\section{MODELAGEM E SIMULAÇÃO}

De acordo com as equações obtidas pela amostragem foi possível desenvolver o modelo que demonstra o comportamento da produção para vidro temperado. Por se tratar de um modelo o mesmo fornece valores próximos aos valores reais, o que possibilitou a criação de 07 cenários. A Figura 11 mostra o Diagrama de Estoque e Fluxo para a produção de vidro temperado. 
No cenário 1 é utilizado as equações de 1 a 12 para entender como o modelo se comporta. A Lapidação, Marcação II, Conferência e Forno apresentaram valores negativos. Os valores negativos representam ociosidade no sistema, ou seja, estão trabalhando abaixo da sua capacidade de operação. Os valores positivos do Corte Automático e Marcação I representam acumulo de atividades, ou seja, metragem de vidro pendente para ser manufaturado por esses setores. Os valores das Vendas são iguais para todos os cenários. O Retrabalho também é igual até o sexto cenário. Tanto o Retrabalho quanto as Vendas interferem diretamente no resultado do Corte Automático, pois os dois alimentam a entrada do Corte Automático. As Figuras 2 a 10 mostram o comportamento para o cenário 1 . Os valores finais para o Cenário 1 são apresentados na Tabela 1.

Tabela 1 - Cenário 1 simulado

\begin{tabular}{cc} 
Setores & Cenário 1 \\
Corte Automático & 5639,71 \\
Marcação I & $-245,848$ \\
Marcação II & 292,321 \\
Conferência & $-196,412$ \\
Forno & $-3947,14$ \\
Vendas & $-1774,47$ \\
Retrabalho Total & 962,653 \\
\hline
\end{tabular}

Fonte: Autoria própria (2018)

Figura 02 - Corte Automático

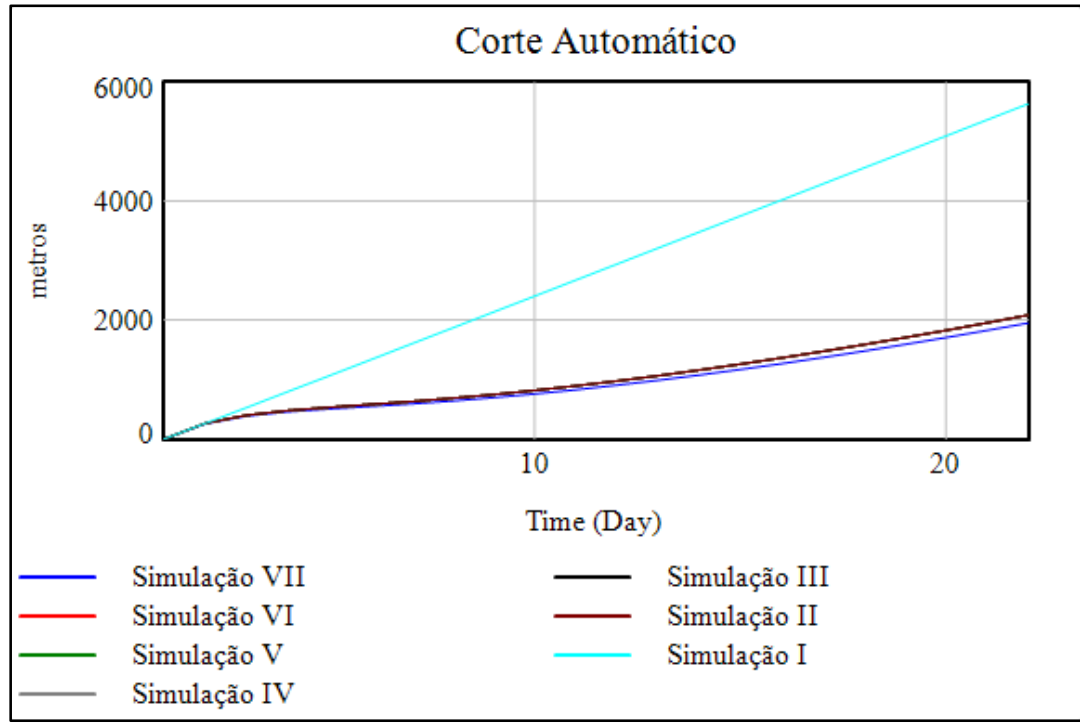

Fonte: Autoria própria (2018) 
Figura 10 - Vendas diárias

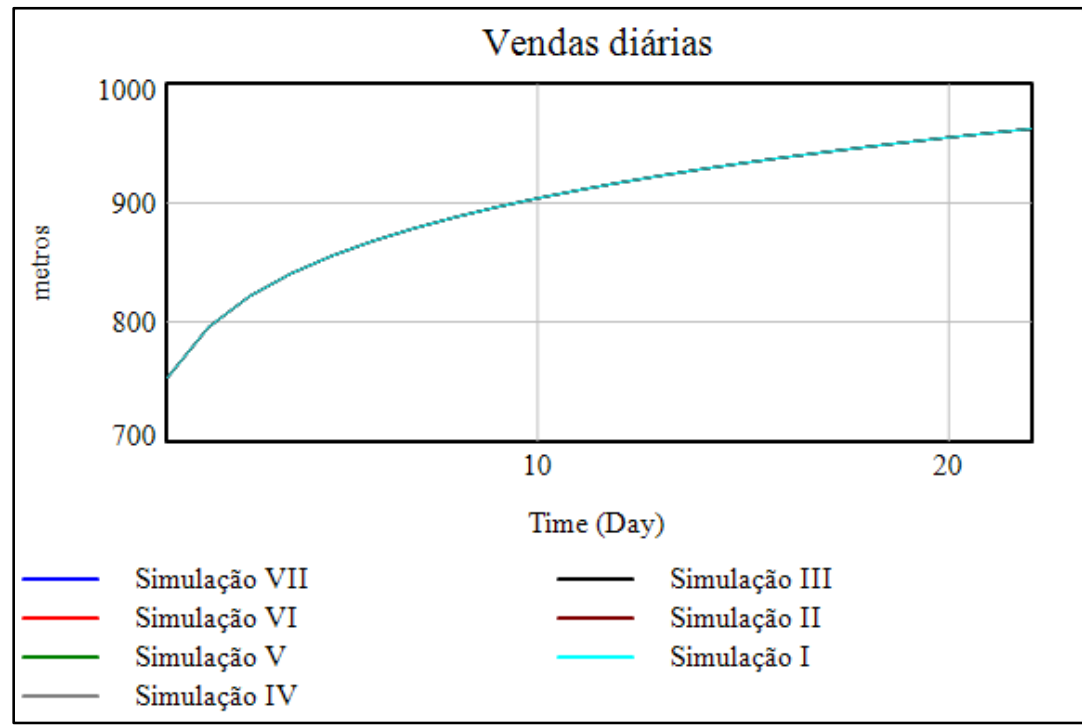

Fonte: Autoria própria (2018)

\section{Cenário 2}

No cenário 2 é introduzido um novo parâmetro para Saída do Corte denominado "Saída Corte Alternativa". É determinado um valor de 850 metros /dia. Esse valor foi considerado como valor ideal. (Valor ideal é diferente de valor ótimo pois para determinar o valor ótimo deveria ser feito o uma otimização para determinar o melhor valor e nesse caso deveria usar programação linear com uma função objetiva). Após a introdução desse valor pode ser percebido até o cenário 6 uma redução de 5639,71 para 2085,03 metros. Essa redução equivale a uma porcentagem de $36 \%$, ou seja, o setor passou a produzir mais com a mesma quantidade de horas com isso houve uma redução na metragem estocada. 0 setor de Lapidação apresentou um aumento devido não ter sido feito nenhuma mudança e os demais setores permanecem inalterados. Essa redução pode ser percebida pela Figura 2. Os valores finais para o Cenário 2 são apresentados na Tabela 2

Tabela 2 - Cenário 2 simulado

\begin{tabular}{cc} 
Setores & Cenário 2 \\
Lapidação & 2085,03 \\
Marcação I & 3308,84 \\
Marcação II & 292,321 \\
Conferência & $-196,412$ \\
Forno & $-3947,14$ \\
Vendas & $-1774,47$ \\
Retrabalho Total & 962,653 \\
\hline
\end{tabular}

Fonte: Autoria própria (2018) 
Figura 03 - Lapidação

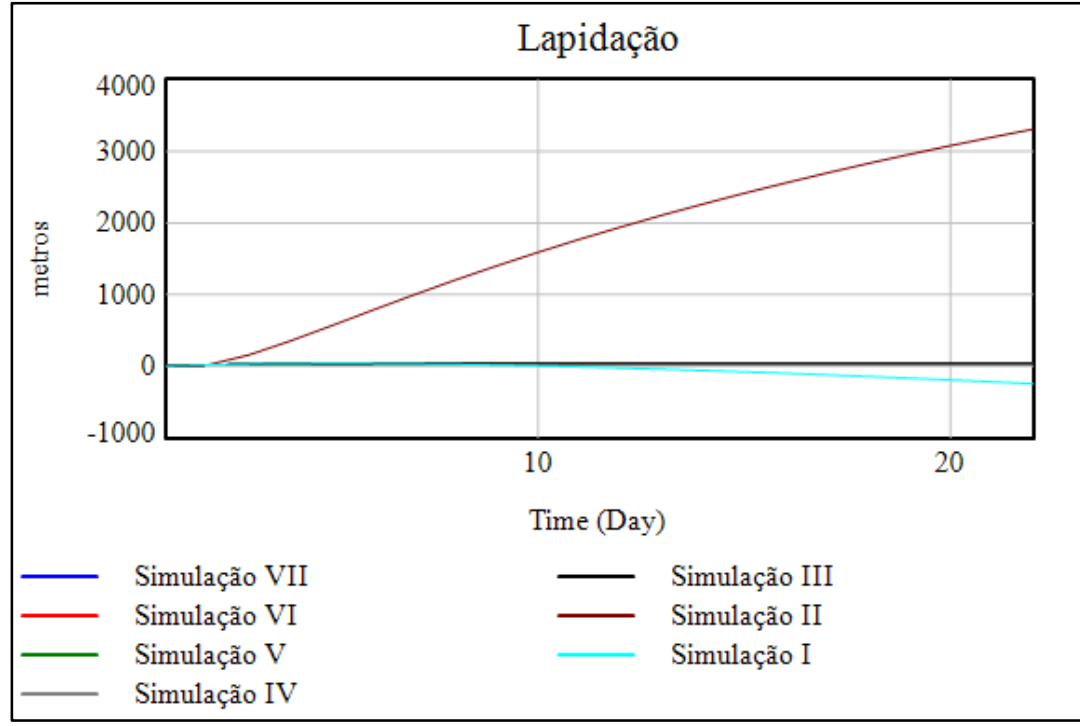

Fonte: Autoria própria (2018)

\section{Cenário 3}

O cenário 3 permanece com os dados do Cenário 2, porém é introduzido a "Saída Lapidação Alternativa". Da mesma maneira que foi proposto para o cenário anterior o valor ideal para a Saída da Lapidação é de 850 metros / dia. 0 valor que era de 3308,84 passa a serem 37,1203 metros / dia, uma redução de $98,88 \%$, ou seja, o setor também passou a produzir mais com o mesmo número de horas dia, que pode ser Observado na Figura 3. A Marcação I e a Marcação II tiveram aumento devido não ter sido feito nenhuma intervenção, os demais setores permanecem os mesmos valores. Os valores finais para o Cenário 3 são apresentados na Tabela 3

Tabela 3 - Cenário 3 simulado

\begin{tabular}{cc} 
Corte Automático & Cenário 3 \\
Lapidação & 2085,03 \\
Marcação I & 37,1203 \\
Marcação II & 2221,98 \\
Conferência & 1145,65 \\
Forno & $-3947,14$ \\
Vendas & $-1774,47$ \\
Retrabalho Total & 962,653 \\
\hline
\end{tabular}

Fonte: Autoria própria (2018) 
Figura 03 - Lapidação

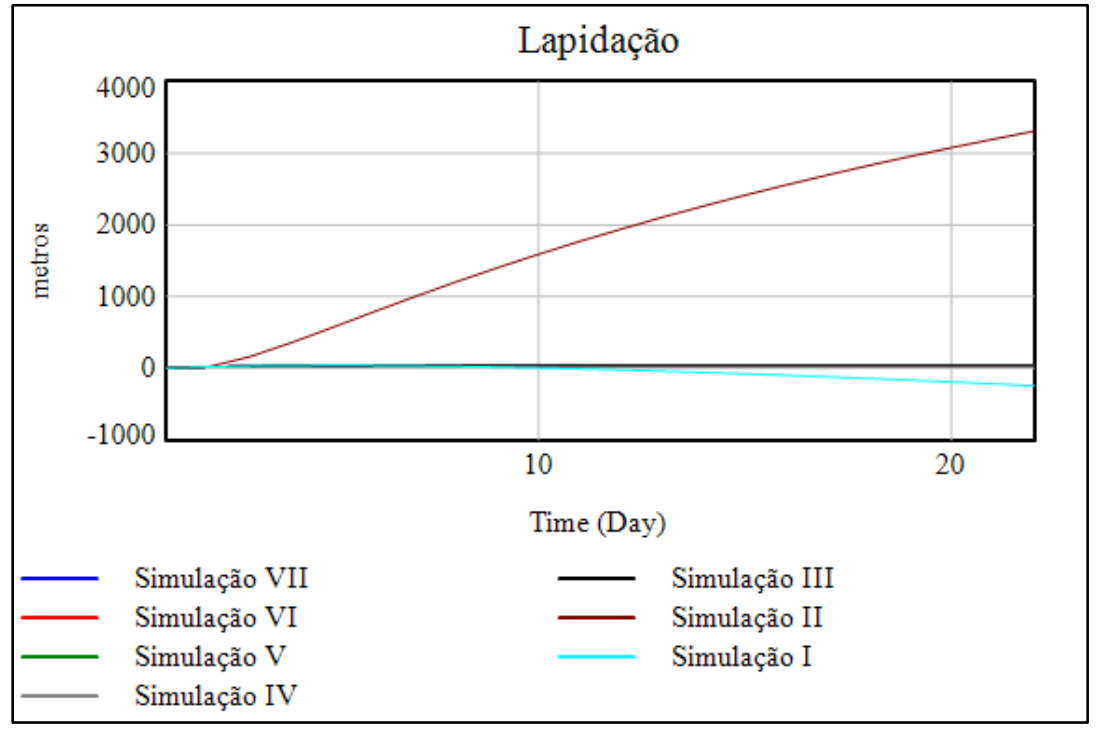

Fonte: Autoria própria (2018)

\section{Cenário 4}

Neste cenário os dados iniciais seguem as definições do cenário 3, acrescido do novo parâmetro para Marcação I. Foi introduzida a "Saída Marcação I Alternativa". O novo valor para Saída Marcação I passa a serem 505 metros / dia. O valor que era de 2221,98 passa a serem 25,7565 metros / dia, uma redução de $98,84 \%$, ou seja, setor produtivo passou a produzir mais com mesmo número de horas, que pode ser observado pela Figura 4. O setor da Conferência e o Setor do Forno tiveram aumento devido não ter sido feito nenhuma intervenção. Os demais setores permaneceram com os mesmos valores. Os valores finais para o Cenário 4 são apresentados na Tabela 4

Tabela 4 - Cenário 4 simulado

\begin{tabular}{cc} 
Serte Automático & Cenário 4 \\
Lapidação & 2085,03 \\
Marcação I & 37,1203 \\
Marcação II & 25,7565 \\
Conferência & 1145,65 \\
Forno & $-1750,92$ \\
Vendas & 421,755 \\
Retrabalho Total & 962,653 \\
\hline
\end{tabular}

Fonte: Autoria própria (2018) 
Figura 04 - Marcação I

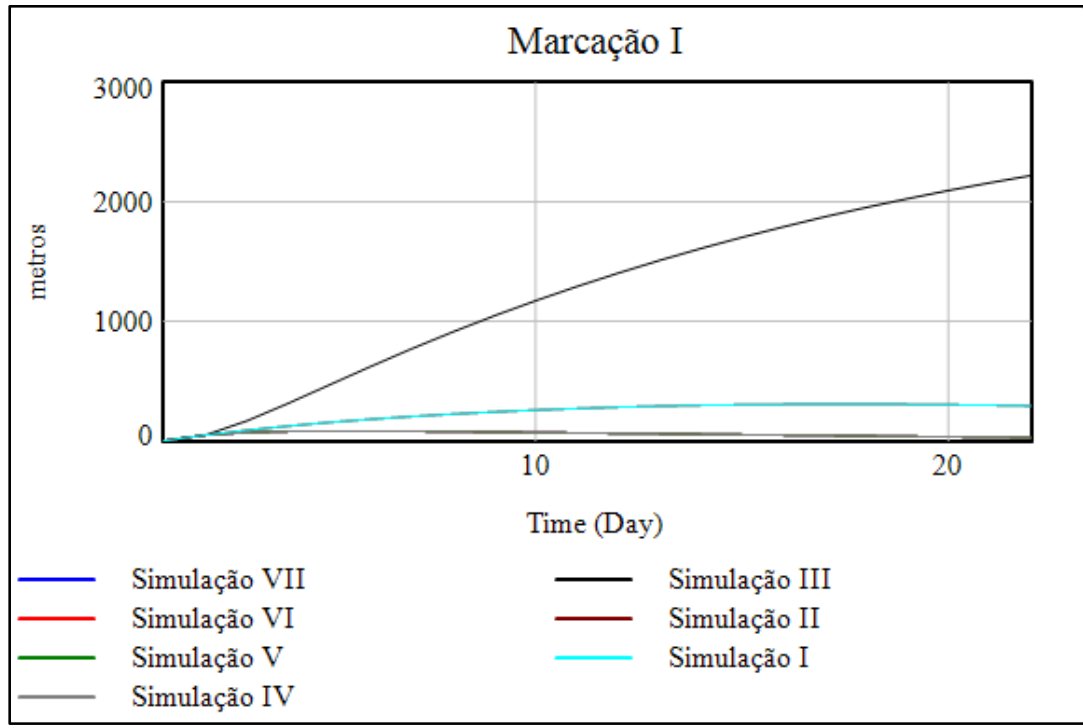

Fonte: Autoria própria (2018)

\section{Cenário 5}

Neste cenário os dados iniciais seguem as definições do cenário 4, acrescido do novo parâmetro para Marcação II. Foi introduzida a "Saída Marcação II Alternativa". O novo valor para Saída Marcação II passa a ser 340 metros / dia. O valor que era de1145, 65 passa a ser 76,4235 metros / dia, uma redução de $93,3 \%$, ou seja, setor produtivo passou a produzir mais com mesmo número de horas, que pode ser observado pela Figura 5. O Setor do Forno teve aumento devido não ter sido feito nenhuma intervenção. Os demais setores permaneceram com os mesmos valores. Os valores finais para o Cenário 5 são apresentados na Tabela 5

Tabela 5 - Cenário 5 simulado

\begin{tabular}{cc} 
Corte Automático & Cenário 5 \\
Lapidação & 2085,03 \\
Marcação I & 37,1203 \\
Marcação II & 25,7565 \\
Conferência & 76,4235 \\
Forno & $-1750,92$ \\
Vendas & 1490,98 \\
Retrabalho Total & 962,653 \\
\hline
\end{tabular}

Fonte: Autoria própria (2018) 
Figura 05 - Marcação II

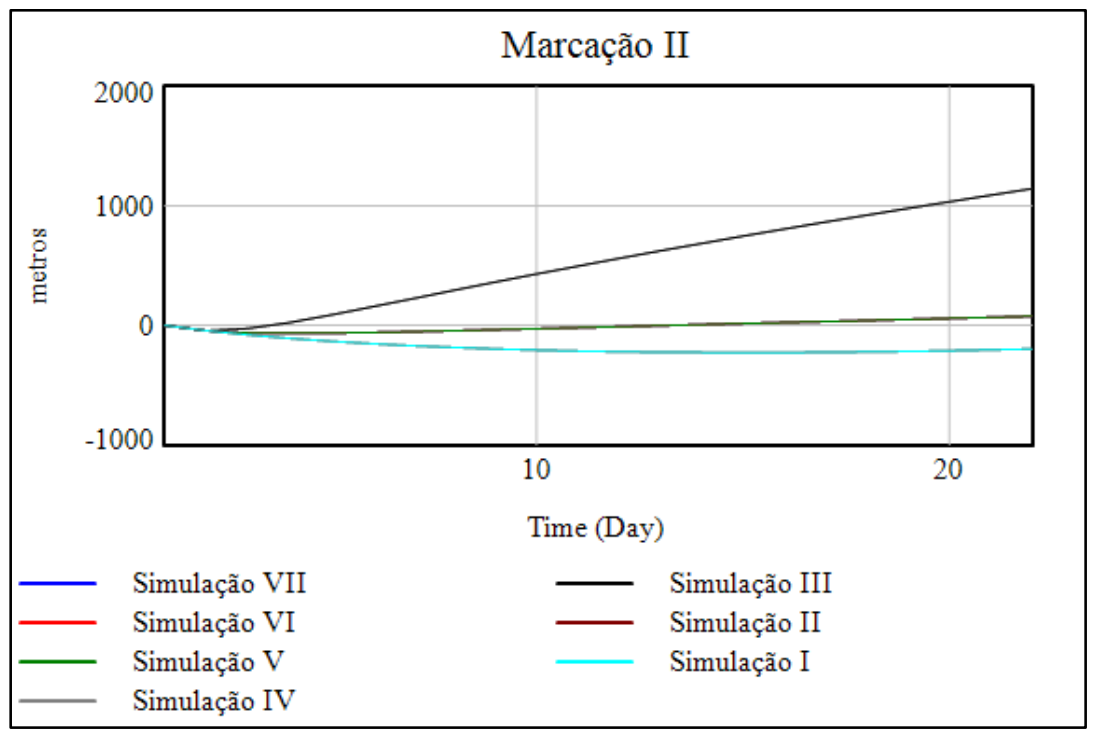

Fonte: Autoria própria (2018)

\section{Cenário 6}

Neste penúltimo cenário os dados iniciais seguem as definições do cenário 5, acrescido do novo parâmetro para Forno. Foi introduzida a "Saída Forno Alternativa". O novo valor para Saída Forno passa a ser 825 metros / dia. O valor que era de1490, 98 passa a ser 57,6201 metros / dia, uma redução de 96,14\%, ou seja, setor produtivo passou a produzir mais com mesmo número de horas, que pode ser observado pela Figura 7. Por ser o último setor não causou aumento em nenhum outro setor, a mudança significativa ocorre na quantidade de "Total de vidro temperado", que estava com um valor final 15546,80 (até a simulação 5) e agora passou a ser 16980,10 o que acarretou em um ganho de 9,22\% que pode ser observado pela Figura 8. Os valores finais para o Cenário 6 são apresentados na Tabela 6

Tabela 6 - Cenário 6 simulado

\begin{tabular}{cc} 
Corte Automático & Cenário 6 \\
Lapidação & 2085,03 \\
Marcação I & 37,1203 \\
Marcação II & 25,7565 \\
Conferência & 76,4235 \\
Forno & $-1750,92$ \\
Vendas & 57,6201 \\
Retrabalho Total & 962,653 \\
\hline
\end{tabular}

Fonte: Autoria própria (2018) 
Figura 06 - Conferência

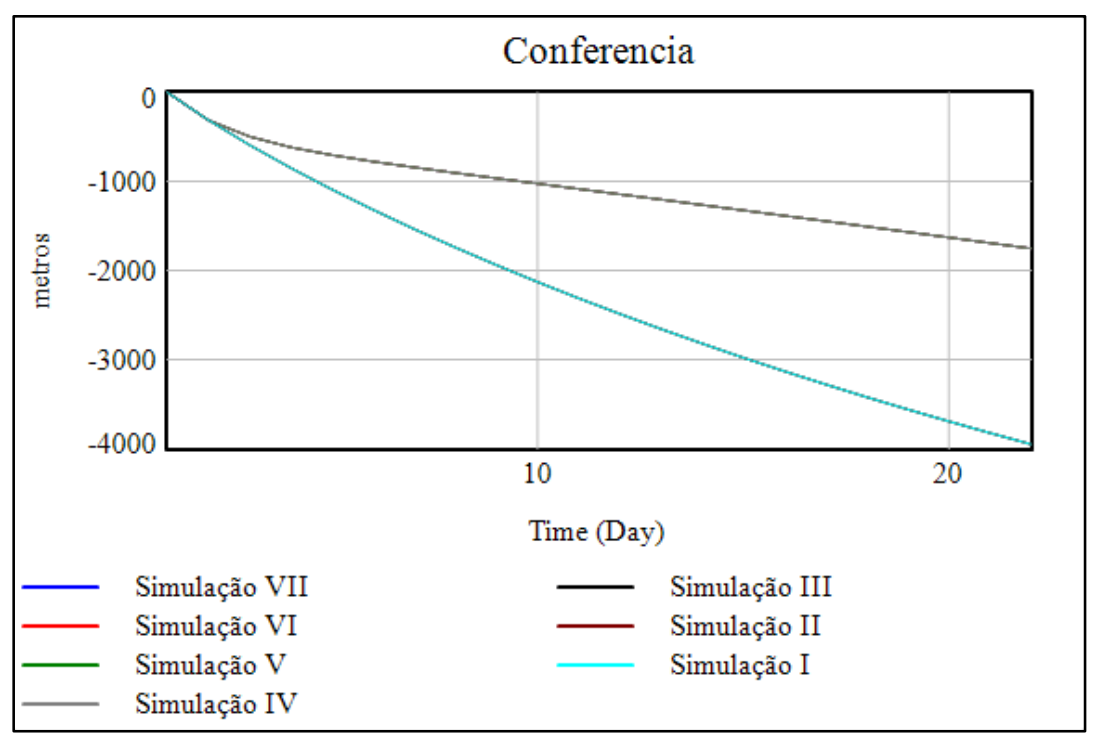

Fonte: Autoria própria (2018)

Figura 07 - Forno

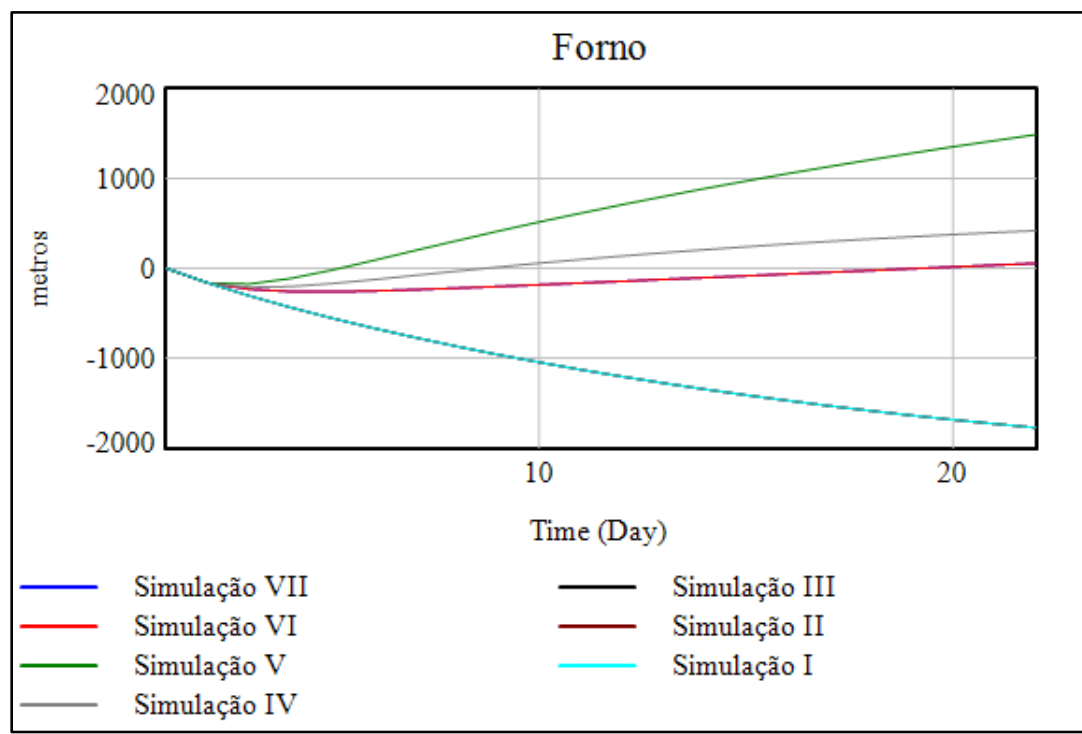

Fonte: Autoria própria (2018) 
Figura 08 - Total de Vidro Temperado

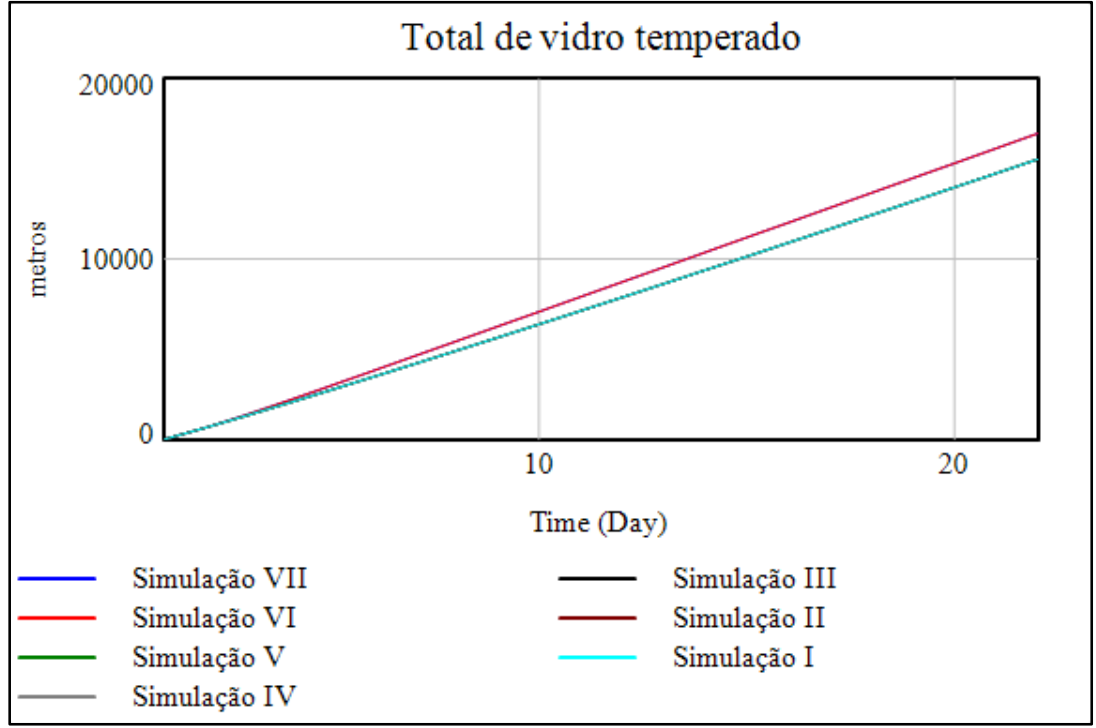

Fonte: Autoria própria (2018)

\section{Cenário 7}

Neste último cenário os dados iniciais seguem as definições do cenário 6 , acrescido de uma redução de $30 \%$ para o retrabalho, a escolha desse valor foi empírica. Essa redução no Corte Automático passou de 2085,03 para 1950,43, o que representa $6,46 \%$ e pode ser observado pelas Figuras 2 e 9 . Os valores finais para o Cenário 7 são apresentados na Tabela 7.

Tabela 7 - Cenário 7 simulado

$\begin{array}{cc}\text { Setores } & \text { Cenário } 7 \\ \text { Corte Automático } & 1950,43 \\ \text { Lapidação } & 37,1203 \\ \text { Marcação I } & 25,7565 \\ \text { Marcação II } & 76,4235 \\ \text { Conferência } & -1750,92 \\ \text { Forno } & 57,6201 \\ \text { Vendas } & 962,653 \\ \text { Retrabalho Total } & 314,06\end{array}$

Fonte: Autoria própria (2018) 
Figura 09 - Retrabalho Total

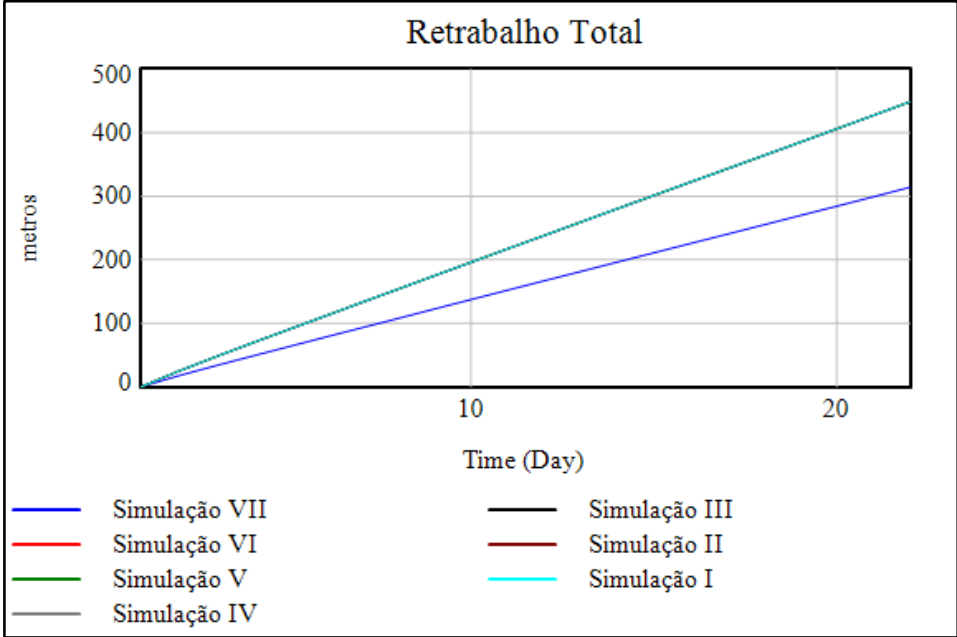

Fonte: Autoria própria (2018)

\section{Análise Dos Cenários Apresentados}

Os 7 cenários apresentados mostram mudanças graduais, o cenário 1 mostra como o sistema se comporta sem nenhuma intervenção, e nele pode ser observado que vários setores estão trabalhando abaixo de sua capacidade o que gera estoque desnecessário e atrasos na produção. A partir do cenário 2 ao 5 houve simulações com mudanças para os setores como Corte, Lapidação, Marcação I e II, essas mudanças podem ser inseridas na prática com reuniões para entender onde está havendo perda de tempo e inserção de metas para produções dia em cada setor. A partir do cenário 6 com o aumento na produção do forno, pode ser percebido um aumento na quantidade de vidro temperado, um ganho $9,22 \%$, valor esse que pode ser considerado expressivo se analisar que não houve aumento na jornada de trabalho e nem contratação de novos funcionários. Vale ressaltar que o valor ideal que foi estipulado sendo de 825 metros /dia está abaixo da capacidade do forno que é de 1000 metros / dia.

Esse balanceamento se deve ao fato de o forno ter a capacidade de temperar 1000 metros dia, porém caso seja utilizado sua capacidade total ele ficará ocioso que poderá causar prejuízo significativo para organização, pois o forno consome energia elétrica e o mesmo quando ligado deve funcionar o horário total de 8 horas diárias.

No cenário 7 , foi colocado uma redução de $30 \%$ de retrabalho. O retrabalho independente de qual valor seja ele é causador de perdas de tempo no processo produtivo pois aquele produto está sendo refeito e acaba tomando o tempo de um produto novo que poderia estar sendo produzido no lugar dele. Retrabalho de $0 \%$ também não existe por mais que as organizações trabalhem com sistemas de qualidade ou Controle Estatístico de Processo (CEP), sempre irá existir algum retrabalho por menor que ele seja. $O$ ideal é que ele seja o mínimo possível por isso a escolha de se usar inicialmente $30 \%$, quando a organização estiver preparada para trabalhar com controles de qualidade mais avançados aí sim poderá ser adotado valores de 80 a $95 \%$. 


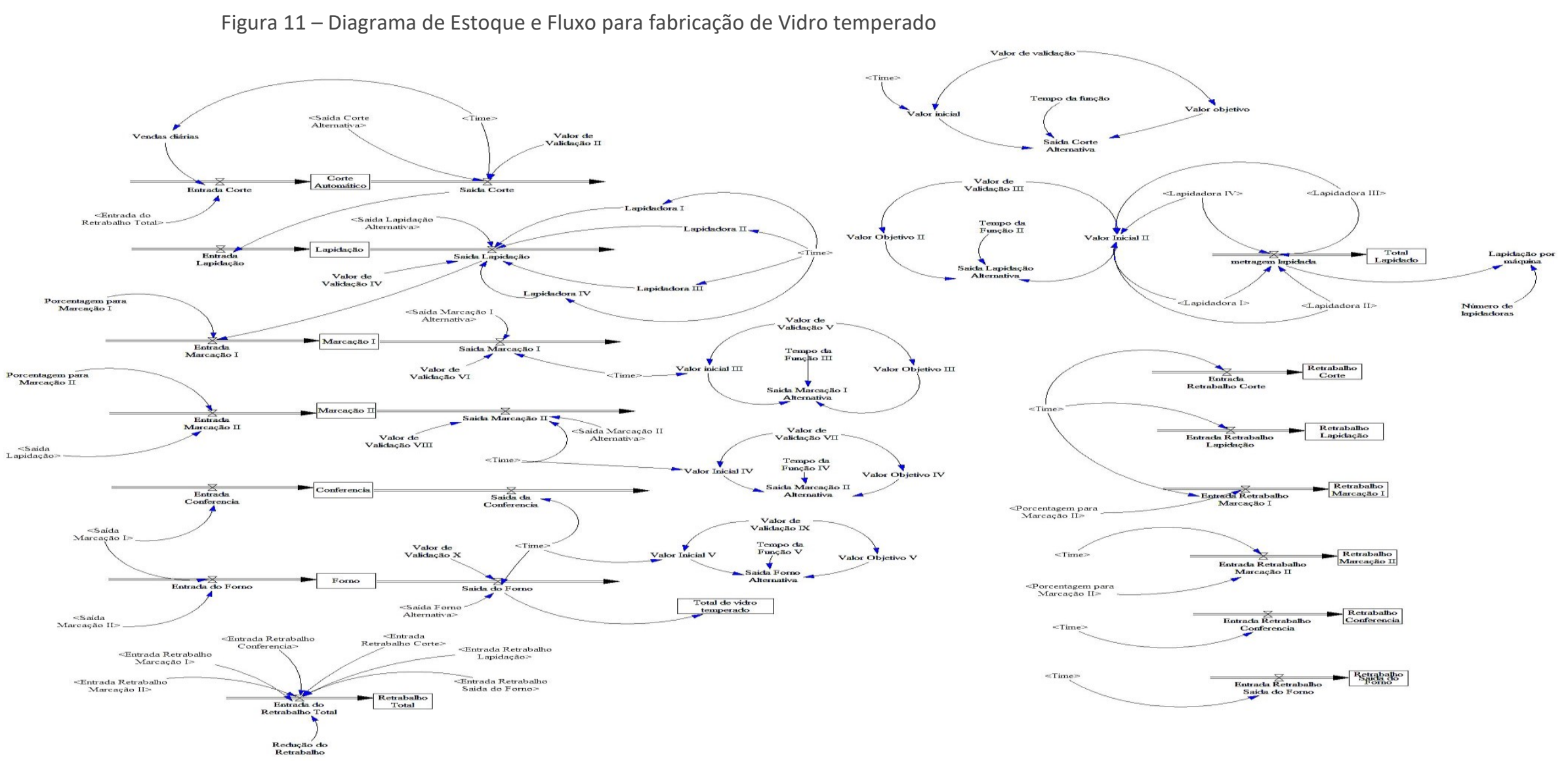

Fonte: Autoria própria (2018) 


\section{CONCLUSÃO}

O presente estudo foi realizado por um período de um mês na organização. Ao simular 07 possíveis cenários percebeu a necessidade de melhorar a produtividade essa por sua vez pode ser alcançada com reuniões nos setores e implementação de metas diárias. Foi possível analisar também que o retrabalho é um fator que atrapalha o processo produtivo e o mesmo quando consegue ser tratado e reduzido proporciona ganhos para organização.

Com a utilização da simulação ficou claro para os gestores que ações eles poderiam tomar para melhorar a produtividade nos setores sem que houvesse a contratação de nova mão - de - obra ou ate mesmo a necessidade de fazer hora extra.

Esse trabalho deixa como ponto a ser estudado, a implementação do Controle Estatístico de Processo no setor produtivo junto com uma nova simulação, para verificar quais os ganhos que o CEP pode agregar para essa empresa. 


\title{
Simulation of the production using technique of systems dynamics in a glass industry: case study in a glass processor
}

\begin{abstract}
Companies are increasingly looking for improvements in their production processes. The identification of bottlenecks or losses in productive processes is often complex to be identified or solved without the aid of simulation software. The processes are often not linear, which makes it difficult for the manager to work with conventional forms of Time Studies, Line Balancing, Flow or Load Balancing, or any other technique that he can not use software for simulation. Simulation is a process of creating and experiencing a system through mathematical models. The system consists of inputs (inputs) and outputs, and they provide a result for some purpose. This paper presents a case study for a glass industry using simulation techniques through the Dynamics of Systems. We simulated 07 scenarios that contemplate or a gradual increase in the productivity of each sector. Of all the scenarios analyzed, the one that presented the best result for production in the furnace sector was the last scenario. This increase was $9.22 \%$ using the same workforce and within the organization's working hours, which is 8 hours per day.
\end{abstract}

KEYWORDS: Modeling. Systems Dynamics. Glass Industrialization. 
ANTÔNIO, L.; JÚNIOR, N.; ANZANELLO, M. J. Comparação De Políticas De Gestão De Estoque Via Simulação De Monte Carlo Comparison Between Inventory Systems Using Monte Carlo Simulation. Revista Gestão Industrial, v. 2011, p. 181-197, 2016.

BOVO, D. Revista Gestão Industrial Estudo De Simulação Da Reconfiguração Do Layout Study Simulation To Reconfigure The Logistics Layout For Cost Reduction And Bottlenecks Elimination . Universidade Tecnológica Federal do Paraná UTFPR, v. 11, p. 148-167, 2015. crossref

CASTRO, T. R. DE C. Planejamento e controle da produção em uma indústria de margarinas. Revista Gestão Industrial, v. 14, n. 1808-0448, p. 1-22, 2018.

crossref

MALDONADO, M. U.; VAZ, C. R. CONTRIBUIÇÕES DA DINÂMICA DE SISTEMAS NA ENGENHARIA DE PRODUÇÃO: ÁREAS POTENCIAIS DE PESQUISA. XXXXVI ENCONTRO NACIONAL DE ENGENHARIA DE PRODUCÃO, p. 1-10, 2016.

OLIVEIRA BERNARDO, G.; RONALDO TAVARES SANTOS, J.; GERALDO MENDES MIRANDA, C. Aplicação Da Dinâmica De Sistemas Na Gestão De Processos De Construção Civil -Utilização Do Software Vensim. XXXVII ENCONTRO NACIONAL DE ENGENHARIA DE PRODUCAO, p. 1-21, 2017.

OMOGBAI, O.; SALONITIS, K. A Lean Assessment Tool Based on Systems Dynamics. Procedia CIRP, v. 50, p. 106-111, 2016. crossref

PEREIRA, M. M.; DANTAS, M. J. P. Aplicação Da Modelagem E Simulação Nos Sistemas De Filas M/M/S- Entendendo a Natureza Da SimulaçãoRevista Produção Online, 2017. crossref

RABELO, F. et al. ANÁLISE COMPARATIVA DE TEORIA DAS FILAS CONCOMITANTE COM SIMULAÇÃO DISCRETA APLICADAS EM FILAS DO TIPO M/M/1. XXXVII ENCONTRO NACIONAL DE ENGENHARIA DE PRODUCAO, p. 1-20, 2017.

RAMON, W.; MACHADO, B. Modelagem E Simulação Do Atendimento Em Um Restaurante Universitário Utilizando O Software Arena. XXXVI ENCONTRO NACIONAL DE ENGENHARIA DE PRODUCÃO Contribuições, p. 1-15, 2016.

RUSIVEL, P. et al. Sistema lean para otimização de recursos em uma indústria moveleira : estudo de caso com foco nas ferramentas da produção enxuta. Revista Gestão Industrial, v. 13, n. 1808-0448, p. 112-140, 2017. crossref 
VINHOTE, M. J.; SILVA, F. J. DA; OLIVEIRA, DA J. M. A. Modelagem e simulação com o Arena para reduzir filas em um restaurante self service.pdf. Revista Gestão Industrial, v. 13, p. 1-14, 2017.

ZHAN, S. F. et al. Dynamic modelling for ecological and economic sustainability in a rapid urbanizing region. Procedia Environmental Sciences, v. 13, n. 2011, p. 242-251, 2012. crossref

Gallegos, R. Simulação da produção utilizando técnica de Dinâmica de Sistemas em uma indústria de vidro: estudo de caso em uma processadora de vidro. R. Gest. Industr., Ponta Grossa, v. 16, n. 3, p. 41-63, Jul./Set. 2020. Disponível em: https://periodicos.utfpr.edu.br/revistagi

Correspondência:

Raphael Gallegos

Rua Frei Gonzaga, número 130, Bairro Mangabeiras, Belo Horizonte, Minas Gerais, Brasil.

Direito autoral: Este artigo está licenciado sob os termos da Licença Creative Commons-Atribuição 4.0 Internacional.

$$
\text { (c) (1) }
$$

